\title{
BMJ Open Community engagement approaches for Indigenous health research: recommendations based on an integrative review
}

\author{
Chu Yang Lin, ${ }^{1}$ Adalberto Loyola-Sanchez, ${ }^{2}$ Elaine Boyling, ${ }^{3}$ Cheryl Barnabe (D) ${ }^{4}$
}

To cite: Lin CY, LoyolaSanchez A, Boyling E, et al. Community engagement approaches for Indigenous health research: recommendations based on an integrative review. BMJ Open 2020;10:e039736. doi:10.1136/ bmjopen-2020-039736

- Prepublication history and additional material for this paper are available online. To view these files, please visit the journal online (http://dx.doi org/10.1136/bmjopen-2020039736).

Received 24 April 2020 Revised 21 0ctober 2020 Accepted 26 0ctober 2020

Check for updates

(C) Author(s) (or their employer(s)) 2020. Re-use permitted under CC BY-NC. No commercial re-use. See rights and permissions. Published by BMJ.

${ }^{1}$ Office of Undergraduate Medical Education, University of Alberta Faculty of Medicine and Dentistry, Edmonton, Alberta,

Canada

${ }^{2}$ Sanchez Department of Medicine, University of Alberta Faculty of Medicine and Dentistry, Edmonton, Alberta,

Canada

${ }^{3}$ Department of Family Medicine, University of Calgary Cumming

School of Medicine, Calgary,

Alberta, Canada

${ }^{4}$ Medicine, University of Calgary Cumming School of Medicine, Calgary, Alberta, Canada

Correspondence to

Dr Cheryl Barnabe;

ccbarnab@ucalgary.ca

\section{ABSTRACT}

Objective Community engagement practices in Indigenous health research are promoted as a means of decolonising research, but there is no comprehensive synthesis of approaches in the literature. Our aim was to assemble and qualitatively synthesise a comprehensive list of actionable recommendations to enhance community engagement practices with Indigenous peoples in Canada, the USA, Australia and New Zealand.

Design Integrative review of the literature in medical (Medline, Cumulative Index to Nursing and Allied Health Literature and Embase) and Google and WHO databases (search cut-off date 21 July 2020).

Article selection Studies that contained details regarding Indigenous community engagement frameworks, principles or practices in the field of health were included, with exclusion of non-English publications. Two reviewers independently screened the articles in duplicate and reviewed full-text articles.

Analysis Recommendations for community engagement approaches were extracted and thematically synthesised through content analysis.

Results A total of 63 studies were included in the review, with 1345 individual recommendations extracted. These were synthesised into a list of 37 recommendations for community engagement approaches in Indigenous health research, categorised by stage of research. In addition, activities applicable to all phases of research were identified: partnership and trust building and active reflection.

Conclusions We provide a comprehensive list of recommendations for Indigenous community engagement approaches in health research. A limitation of this review is that it may not address all aspects applicable to specific Indigenous community settings and contexts. We encourage anyone who does research with Indigenous communities to reflect on their practices, encouraging changes in research processes that are strengths based.

\section{INTRODUCTION}

Indigenous populations of Canada, Australia, New Zealand and the USA share common histories of colonisation, with persistent and ongoing disempowerment to maintain the status quo, and with significant impacts on health and wellness outcomes. Research
Strengths and limitations of this study

- The integrative review design, which is a literature synthesis method, permitted us to systematically review and produce qualitative syntheses from the existing literature.

- Both academic-based literature and grey literature sources were searched to include diverse research approaches and audiences.

- Our synthesis of principles was completed through a thematic analysis that produced a comprehensive list of practical, action-oriented recommendations for researchers to appropriately engage with Indigenous peoples.

- Recommended actions reflect descriptions made by primary authors of included articles, and may unintentionally exclude necessary strategies.

- We restricted studies to those involving Indigenous populations of Canada, Australia, New Zealand and the USA and health-specific research only.

provides the opportunity to understand and resolve disparities, yet research involving Indigenous communities has been linked to research fatigue, ${ }^{1}$ the misuse of genetic samples from Indigenous peoples ${ }^{2}$ and an approach that is rooted in community deficits rather than strengths. ${ }^{3}$ Perhaps it is for these reasons that many communities have developed a fear of the term 'research', ${ }^{4}$ and have viewed this process as an extension of colonialism. ${ }^{5}$ Negative examples of research being conducted in Indigenous communities overshadow positive ones, and have prompted the establishment of guidelines for Indigenous health research by the tri-council research bodies in Canada, ${ }^{6}$ enactment of the Ownership, Control, Access and Possession principles for research involving First Nations People of Canada, ${ }^{7}$ and institutional review boards by various tribal regions in the USA. ${ }^{8}$ Despite these measures, a recent systematic review surveying patterns of community engagement in arthritis studies in the 
USA, Canada, Australia and New Zealand produced by our research group found that the majority of research processes continue to nominally involve Indigenous peoples at meaningful levels, ${ }^{9}$ leading to minimal benefit for the participants and communities involved.

One way to move forward is to engage in meaningful collaborations with communities ${ }^{1}$ throughout the research process, including stages of identifying and addressing relevant health concerns, to data collection, interpretation of results and utilisation of results together with those that are impacted by it. This represents an entry point to 'decolonising methodologies', ${ }^{10}$ which requires a shift of typical power from the researcher to the community, and prioritising community needs rather than researcher interests. In our experiences in facilitating Indigenous health research in our local environment, we have observed that there is interest from Indigenous and non-Indigenous researchers to learn how to enact these principles, yet with a general uncertainty on how to do so. This is supported by recent literature contributions across different disciplines and methodological approaches that provide ideas for improved research and engagement practices with Indigenous communities. ${ }^{11} 12$ There is however a paucity of comprehensive recommendations for community engagement approaches with Indigenous peoples in the existing literature, and an inconsistent reporting requirement for community engagement practices among journal publishers.

The purpose of this integrative review was to produce a comprehensive list of recommendations for the engagement of Indigenous communities in health research, through a systematic search of the literature and subsequent qualitative synthesis. This would support paradigmshifting research practices that value community input while minimising risks of unintended harms and consequences for Indigenous communities.

\section{METHODS}

\section{Identification of the existing literature}

We used an 'integrative review' methodology, a wellestablished method to systematically review and produce qualitative syntheses from the existing literature. ${ }^{13} \mathrm{We}$ summarised principles, existing recommendations and strategies for community engagement with Indigenous peoples in Canada, the USA, Australia and New Zealand, in order to generate a comprehensive list of recommendations for researchers. The literature search was conducted in Medline, Cumulative Index to Nursing and Allied Health Literature (CINAHL), and Embase databases, devised with the help of a medical librarian. A grey literature search was performed through Google search engine and the WHO database. All searches were performed from each database inception (Medline: 1946; CINAHL: 1937; Embase: 1974) up to 21 July 2020. There were no restrictions on study type, publication status or publication year. Selection was restricted to English language studies. A summary of terms used during our literature search strategy to identify manuscripts on community engagement (and related concepts of community-based research and participatory action research), guidelines/ recommendations and Indigenous peoples are listed in table 1 . The full search strategy is available in online supplemental file 1, and the review protocol is available by contacting the corresponding author.

\section{Study selection}

The titles and abstracts of retrieved studies were screened in duplicate by two members of our research team (CYL and AL-S) following specific inclusion and exclusion criteria (table 2). These same two researchers independently conducted a full-text review of the manuscripts that fulfilled our inclusion criteria.

\section{Data collection process}

Full-text manuscripts meeting the inclusion criteria and not excluded were reviewed and general information on the study was extracted, including author, year of publication, journal, Indigenous coauthorship or endorsement, methodology, Indigenous population involved, country of origin, name of guideline or framework and health area. We then extracted statements about strategies and recommendations for community engagement, only if they were actionable, implying that purely theoretical statements were not considered. Data collection was completed independently and in duplicate by two reviewers (CYL and

\begin{tabular}{|c|c|c|}
\hline Medline, CINAHL and Embase & Google & WHO database \\
\hline $\begin{array}{l}\text { "Community Engagement" OR "Action Research" } \\
\text { OR "Community-Based Participatory Research" OR } \\
\text { "Participatory Research" OR "Community-Based } \\
\text { Research" } \\
\text { AND } \\
\text { "Guideline" OR "Overview" OR "Principles" OR } \\
\text { "Framework" OR "Recommendation" } \\
\text { AND } \\
\text { "Indigenous" OR "Aborigin*” OR "First Nation" OR } \\
\text { "Inuit" OR "Metis" }\end{array}$ & $\begin{array}{l}\text { "Aboriginal engagement strategy } \\
\text { health" OR "Indigenous community } \\
\text { engagement health" OR "Indigenous } \\
\text { community engagement health } \\
\text { university" }\end{array}$ & $\begin{array}{l}\text { "Indigenous action research" } \\
\text { OR "Indigenous Community } \\
\text { Engagement" }\end{array}$ \\
\hline
\end{tabular}

CINAHL, Cumulative Index to Nursing and Allied Health Literature. 
Table 2 Inclusion and exclusion criteria

\begin{tabular}{ll}
\hline Inclusion criteria & Exclusion criteria \\
\hline $\begin{array}{l}\text { Publications detailing community engagement } \\
\text { frameworks and/or principles }\end{array}$ & $\begin{array}{l}\text { Primary health studies that did not have actionable strategies as } \\
\text { recommendations after reflecting on their experience of applying community } \\
\text { engagement strategies }\end{array}$ \\
\hline Publications concerning Indigenous communities & $\begin{array}{l}\text { Any other type of publication without specific, actionable strategy/ } \\
\text { principles/guidelines }\end{array}$ \\
\hline Publications on health & $\begin{array}{l}\text { Publications outside the health field } \\
\text { Publications not including Canada, the USA, New Zealand or Australia } \\
\text { Non-English publications }\end{array}$ \\
\hline
\end{tabular}

EB) through a piloted form on Microsoft Word (Washington, 2018), and consensus was reached without the involvement of a third party. As the intent of our review was to identify community engagement recommendations employed in different research studies, the quality of the studies in relation to their primary objective was not assessed.

\section{Qualitative synthesis of community engagement recommendations}

The extracted recommendations for community engagement approaches were synthesised thematically using Dedoose qualitative software (Los Angeles, 2018). Initially, two researchers (CYL and AL-S) conducted a thematic analysis of five randomly selected manuscripts, ${ }^{14-18}$ which represented studies conducted in different conditions, with variations in research activities, years of study and countries of research. Using a categorisation method, ${ }^{19}$ the researchers generated a list of themes based on the stage of research for which recommendations were most relevant. Subsequently, all extracted actions were assigned to themes by the same two researchers independently. Revisions to the initial themes were constantly performed throughout the thematic analysis as new insights emerged and to accommodate for all of the recommendations identified. Throughout the process, each set of actions assigned to respective themes were further condensed into single statements according to their similarity and complementarity in order to produce a concise yet comprehensive list of recommendations for community engagement with Indigenous peoples, using an Excel spreadsheet (Washington, 2018). The researchers then converged their analysis; once this synthesis strategy was completed, an expert Indigenous scholar (CB) reviewed all initial extracted actions, confirmed the identified themes and categorisation procedures and undertook a final synthesis to generate a concise list of recommendations to be enacted within Indigenous health research.

\section{RESULTS}

\section{Study selection}

A total of 393 manuscripts were screened for title and abstract relevancy and 263 were removed as they did not fulfil the inclusion criteria. A total of 130 full texts were further reviewed and 67 were removed as they fulfilled the exclusion criteria. A total of 63 studies were included in the qualitative synthesis (figure 1).

\section{Process of qualitative synthesis of the recommendations}

From the 63 included studies, ${ }^{11} 14-1820-75$ a total of 1345 actionable community engagement recommendations were extracted, with an average of 21 statements extracted per study. Study characteristics are found in table 3 . Following the first thematic analysis, the 1345 recommendations were synthesised into 213 recommendations. The final synthesis step resulted in 37 main recommendations, categorised by the research stage and topic related to community engagement, which is summarised below (table 4).

\section{Recommendations by stage of research}

'Preparation and learning': This stage includes recommendations for the researcher to gain knowledge about the history of colonisation with its negative impact on Indigenous peoples' health, as well as the local customs and history of the Indigenous communities to be engaged. The researcher should also understand the tensions of research in Indigenous communities, and be accepting the Indigenous ways of learning and knowing. It is also critical for the researcher to have in-depth knowledge of relevant research ethics, at the institutional and community levels. One notable example in this phase of the research is to be careful with the use of language and terminologies when communicating, avoiding terms that might be viewed as colonising (eg, terms such as 'occupation' to describe jobs/careers may trigger negative responses). ${ }^{65}$ This requires researcher education and sensitivity training. ${ }^{61}$

'Establish relationship and research needs': Recommendations in this stage stress the importance of appropriately establishing relationships with the community and its leadership. These relationships should be entered with a longitudinal commitment, and with the intention of being an ally rather than with a 'saviour' ethos. One way to establish genuine relationships with communities is by honouring welcoming practices which might include hosting a meal in the researchers' home, sharing meals and providing appropriate gifts as initial friendly gestures. ${ }^{23}$ Additionally, individual nations will 


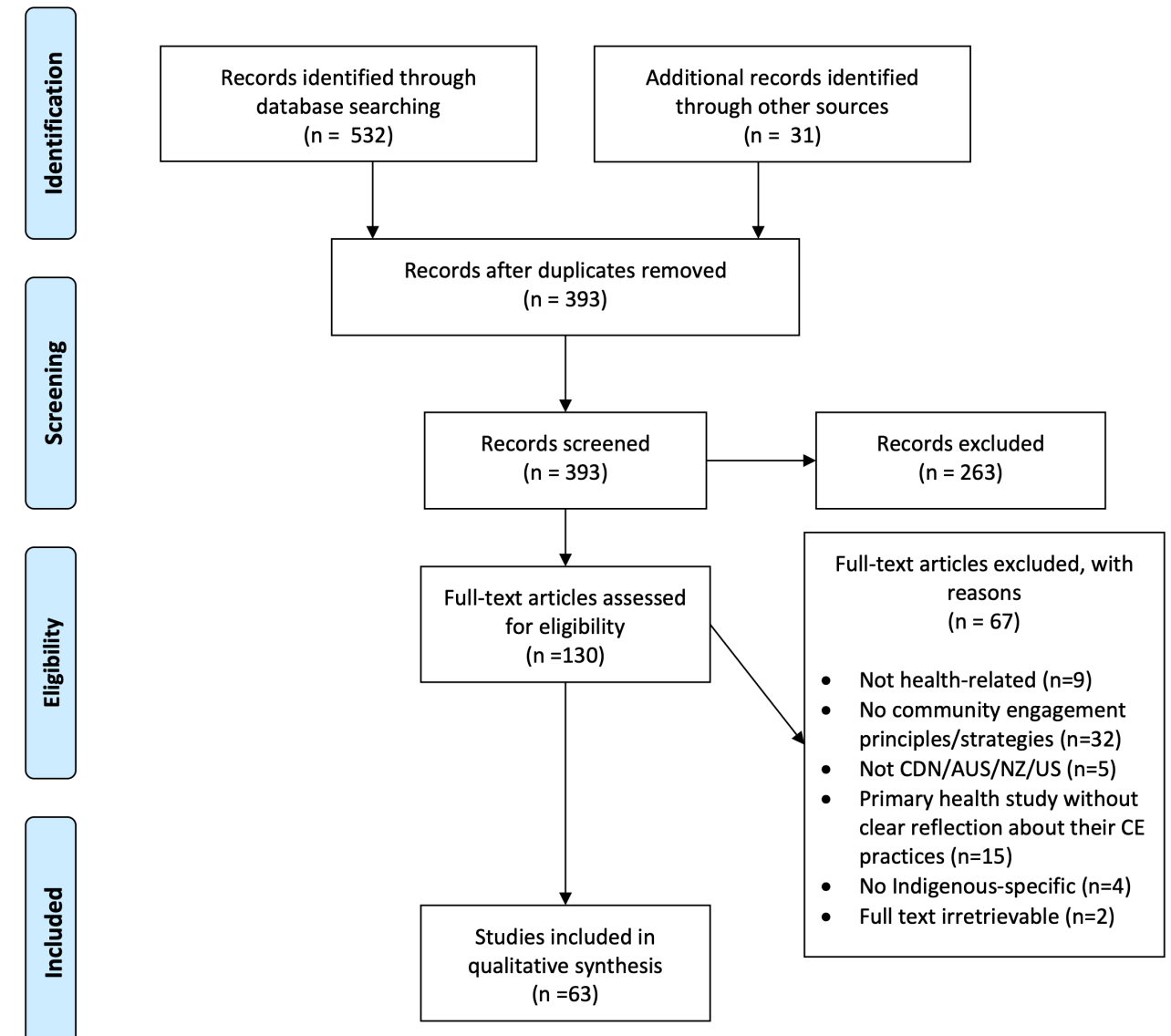

Figure 1 Study selection. Adapted from: Moher et al. ${ }^{77}$ AUS, Australia; CDN, Canada; CE, community engagement; NZ, New Zealand; US, the USA.

have protocols and expectations for beginning and establishing the relationship, and expertise from others should be sought. If there is acceptance of the researcher by the community and its leadership, then discussions to learn about community needs is prioritised, rather than the researcher determining the topic or a preset research agenda. Formal approval processes to proceed with research will be determined by the community. The researcher may then proceed with broader community engagement, and formalisation of the research team.

'Research activities': This stage includes determining the research approach, agreeing to budgets, conducting research with ethical processes and addresses employment of community members, recruitment of research participants and data collection. It is critical to conduct the research within a clear ethical framework, including approaches to research that are congruent with the specific Indigenous communities' values and culture and that consider Indigenous peoples' strengths. In addition, the recommendations promote the importance of considering the costs of initiating and maintaining community participation, especially to facilitate individual participation in research and hiring community members to do different research activities. Research can be burdensome to participants, and it is important to keep the data collection process efficient to minimise fatigue. Any instruments used for the research should be user friendly, and are devoid of jargon. In one health promotion project, researchers designed locally relevant pamphlets relating to influenza prevention, which were easily relatable to community members. Several years later, these pamphlets were still circulating in the community. ${ }^{34}$ Finally, it is critical to monitor the process of research, respond to concerns and feedback expressed by leadership and the community and communicate throughout the project. This is particularly important for projects involving biospecimens of Indigenous communities, and will require iterative feedback sessions through community workshops, tribal meetings and presentations to communities. ${ }^{26}$

'Analysis and interpretation': Community representatives and leadership remain involved in knowledge exchange dynamics in the process of analysing and interpreting data. The researcher should privilege Indigenous knowledge and views, and identify emergent community benefits of the research. This can be done by directly holding community meetings and workshops that aim to elicit feedback, or by directly inviting community input on data generated by the research. ${ }^{69}$ One author had recommended that researchers develop personal responsibility for the long-term implications of the generated data. ${ }^{57} \mathrm{It}$ might be irresponsible to represent an entire community when only a small number of individuals are impacted by a medical condition. In addition, secondary analysis 


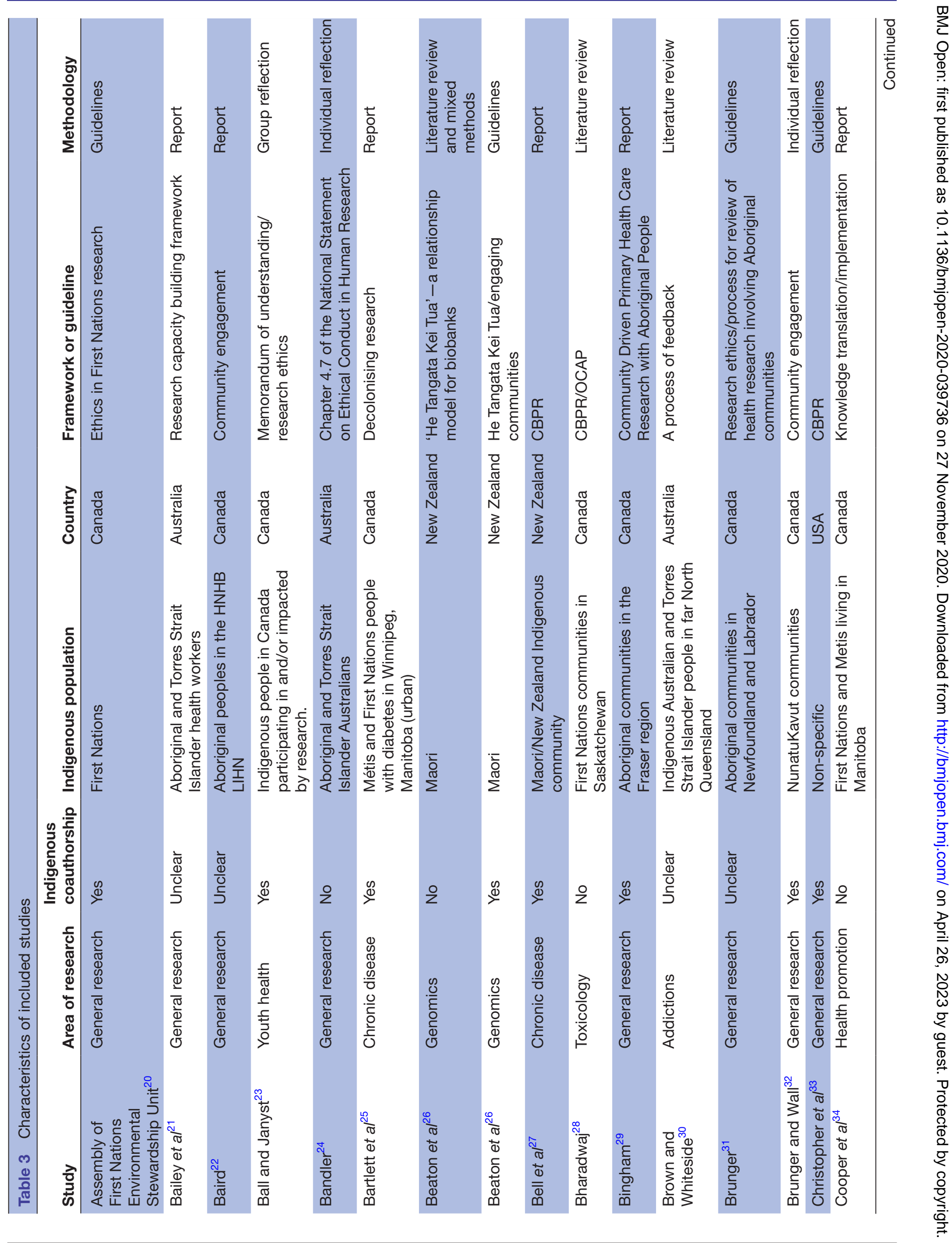




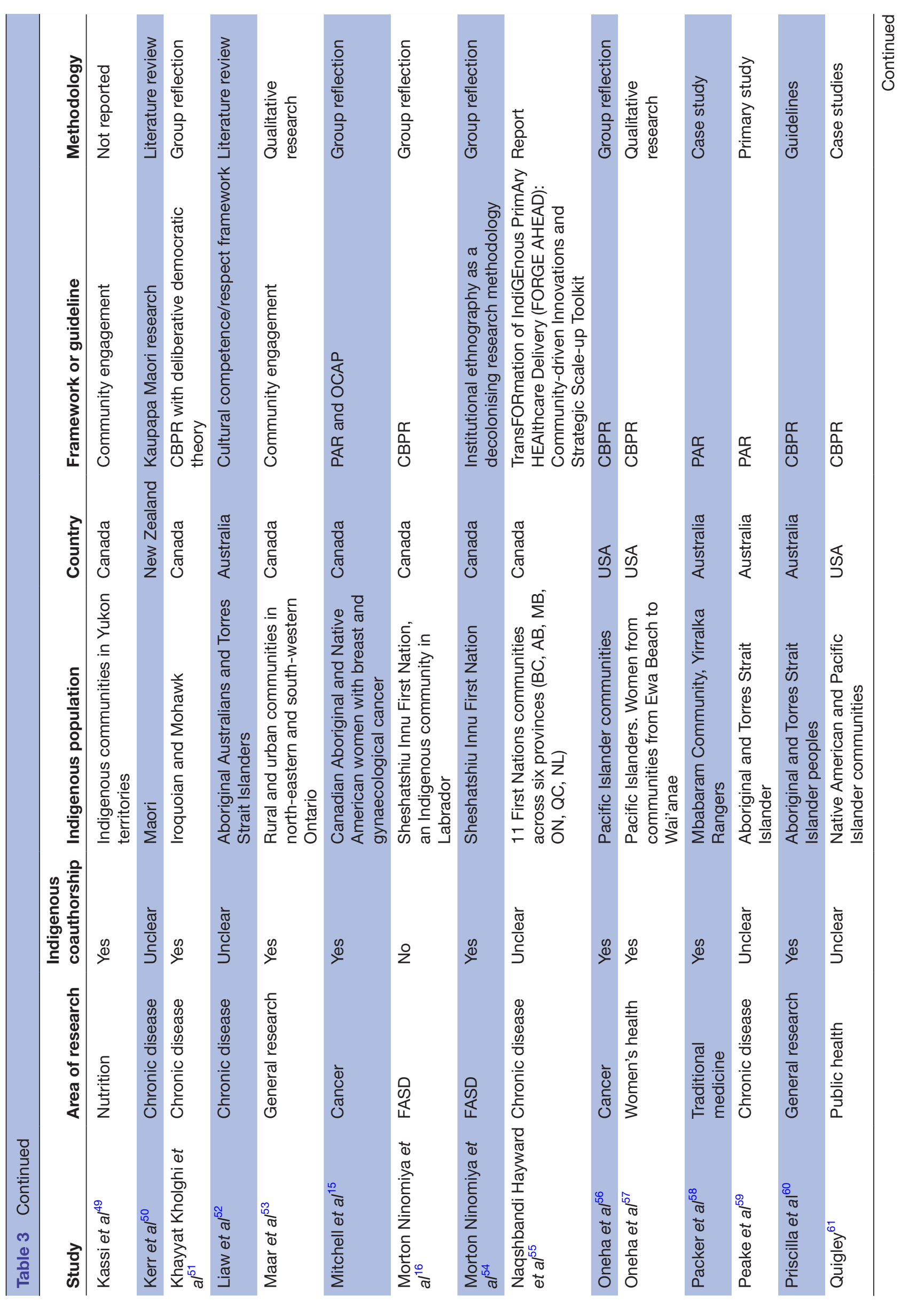

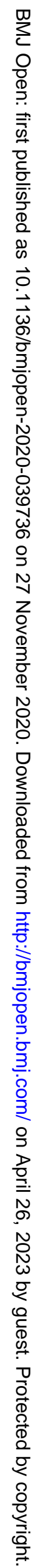




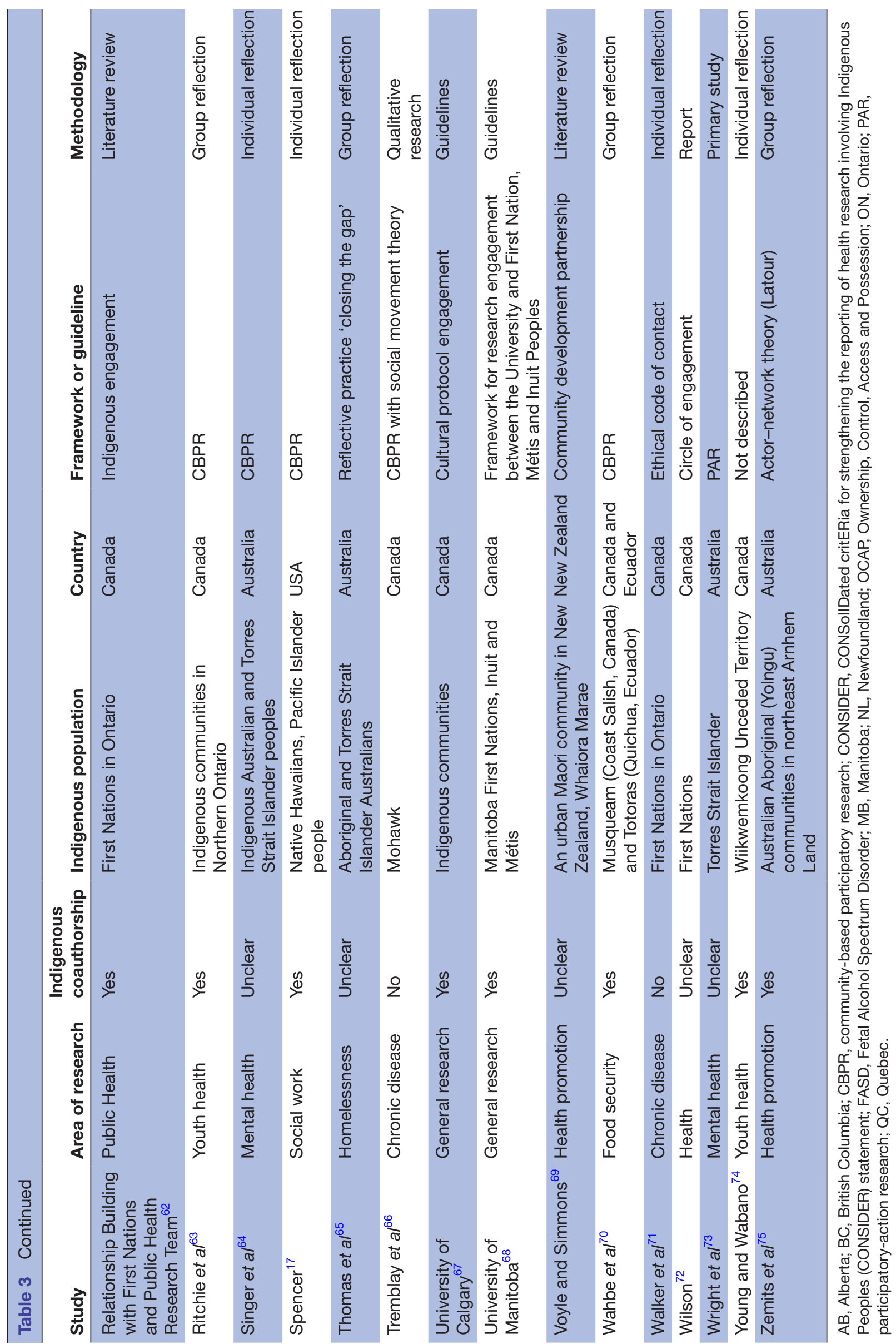


Table 4 Community engagement approaches in Indigenous health research

\begin{tabular}{|c|c|c|}
\hline Stage & Topic & Statement \\
\hline \multirow[t]{2}{*}{ Preparation and learning } & $\begin{array}{l}\text { Knowledge of } \\
\text { Indigenous peoples }\end{array}$ & $\begin{array}{l}\text { Seek opportunities to participate in cultural sensitivity and competency } \\
\text { training to gain knowledge in Indigenous peoples' history. } \\
\text { Understand the relationship between colonialism and the health of } \\
\text { Indigenous populations, including the effects of intergenerational trauma, } \\
\text { power differentials and identity loss. } \\
\text { Become familiar with local Indigenous communities' contexts and } \\
\text { protocols. }\end{array}$ \\
\hline & Research ethics & $\begin{array}{l}\text { Gain knowledge of the ethical principles developed by Indigenous. } \\
\text { organisations and funding bodies } \\
\text { Determine ethical approval processes and requirements at both at the } \\
\text { institutional and local community level. }\end{array}$ \\
\hline & $\begin{array}{l}\text { Determine needs and } \\
\text { role for research }\end{array}$ & $\begin{array}{l}\text { Hear from leadership and community what is needed to meet their } \\
\text { determined health agenda. } \\
\text { Identify if there is leadership and community interest in research activities } \\
\text { to meet their health agenda. }\end{array}$ \\
\hline & Leadership approval & $\begin{array}{l}\text { Secure approval from community leadership entrusted with the authority } \\
\text { to confirm engagement in research. } \\
\text { Develop terms of reference or a memorandum of understanding for all } \\
\text { aspects of the proposed research. This document should be refined } \\
\text { through an iterative process and focused on mutual agreement for all } \\
\text { outcomes and benefits. }\end{array}$ \\
\hline & $\begin{array}{l}\text { Budgetary } \\
\text { considerations }\end{array}$ & $\begin{array}{l}\text { Appropriately estimate costs of conducting community-based research. } \\
\text { Transfer funds to the community to support the research process. }\end{array}$ \\
\hline & $\begin{array}{l}\text { Ethical research } \\
\text { processes }\end{array}$ & $\begin{array}{l}\text { Clarify what data can be collected. } \\
\text { Be honest in disclosing risks of research. } \\
\text { Protect the privacy of participants, and respect wishes for individual and } \\
\text { community identification. }\end{array}$ \\
\hline & $\begin{array}{l}\text { Employment of } \\
\text { community members }\end{array}$ & $\begin{array}{l}\text { Hire community members and support capacity-building and self- } \\
\text { determination activities. }\end{array}$ \\
\hline & $\begin{array}{l}\text { Participant recruitment } \\
\text { and data collection }\end{array}$ & $\begin{array}{l}\text { Use strategies to facilitate participation in research. } \\
\text { Be efficient in research activities to minimise burden to individuals and } \\
\text { the community. }\end{array}$ \\
\hline & $\begin{array}{l}\text { Evaluating the research } \\
\text { process }\end{array}$ & $\begin{array}{l}\text { Continuously monitor the research process and respond to feedback } \\
\text { from leadership and the community. } \\
\text { Ensure ongoing relationship building. } \\
\text { Reassess the appropriateness of continuing the research project. }\end{array}$ \\
\hline
\end{tabular}


Table 4 Continued

\begin{tabular}{|c|c|c|}
\hline Stage & Topic & Statement \\
\hline \multirow[t]{2}{*}{$\begin{array}{l}\text { Analysis and } \\
\text { interpretation }\end{array}$} & Collective interpretation & $\begin{array}{l}\text { Interpret findings and results along with community members, privileging } \\
\text { Indigenous knowledge and views. } \\
\text { Identify benefits and outcomes of the research, and potential implications } \\
\text { of the findings. }\end{array}$ \\
\hline & $\begin{array}{l}\text { Leadership review and } \\
\text { interpretation }\end{array}$ & $\begin{array}{l}\text { Seek feedback from community leadership about the results and their } \\
\text { implications and provide space for two-way knowledge transfer. }\end{array}$ \\
\hline \multirow{2}{*}{$\begin{array}{l}\text { Dissemination and } \\
\text { utilisation of results }\end{array}$} & $\begin{array}{l}\text { Communication of } \\
\text { results }\end{array}$ & $\begin{array}{l}\text { If approved to disseminate results in academic and public settings, } \\
\text { ensure all products have been reviewed and approved by community } \\
\text { leadership and members, with opportunity for coauthorship, and that } \\
\text { ownership of data remains with communities. } \\
\text { If approved to disseminate results to community, ensure all products } \\
\text { are accessible and use methods of communication appropriate to the } \\
\text { community. }\end{array}$ \\
\hline & $\begin{array}{l}\text { Attribution of benefits } \\
\text { of research }\end{array}$ & $\begin{array}{l}\text { Be transparent and share benefits of any commercialisation that came } \\
\text { about as a result of Indigenous data. }\end{array}$ \\
\hline
\end{tabular}

of data should occur only if explicit permission has been provided by the community on a case-by-case basis.

'Dissemination and utilisation of results': Here, a fundamental guiding principle that empowers Indigenous communities is that they hold the final voice to approve research results in any form before they are disseminated and used. We stress the importance of having clear and transparent processes to communicate the research results to communities, under an ethics framework of community ownership. A Canadian study examining diabetes in Indigenous populations deployed a transparent framework, whereby the study would not be published beyond what is required by the funding agency, if any of the community members had rejected the results. ${ }^{46}$

\section{Approach to community engagement and list of recommendations}

Two overarching themes for community engagement with Indigenous peoples were identified, which include recommendations that are pertinent to enact at all stages of a research project: 'partnership and trust' and 'active reflection' (figure 2). Every stage of a research project includes the potential to increase Indigenous communities' capacity to address their health issues, strengthen the relationships between community and researchers and to equilibrate power and knowledge between these two parts. Consequently, it is recommended under the theme of 'partnership and trust' to always aim to build partnerships with community members aiming for mutual benefit and trust, based on principles of Indigenous autonomy, community participation, capacity building, respect, reciprocity, responsibility, advocacy and power redistribution during decision-making. In addition, it is essential for researchers to engage in a continuous process of self-reflection throughout all research stages, in order to recognise individual preconceptions and worldviews, and transcend these to collaborate with community members to produce knowledge that can be shared and accepted by all. Therefore, under the theme of 'active reflection' it is recommended that researchers actively reflect on their

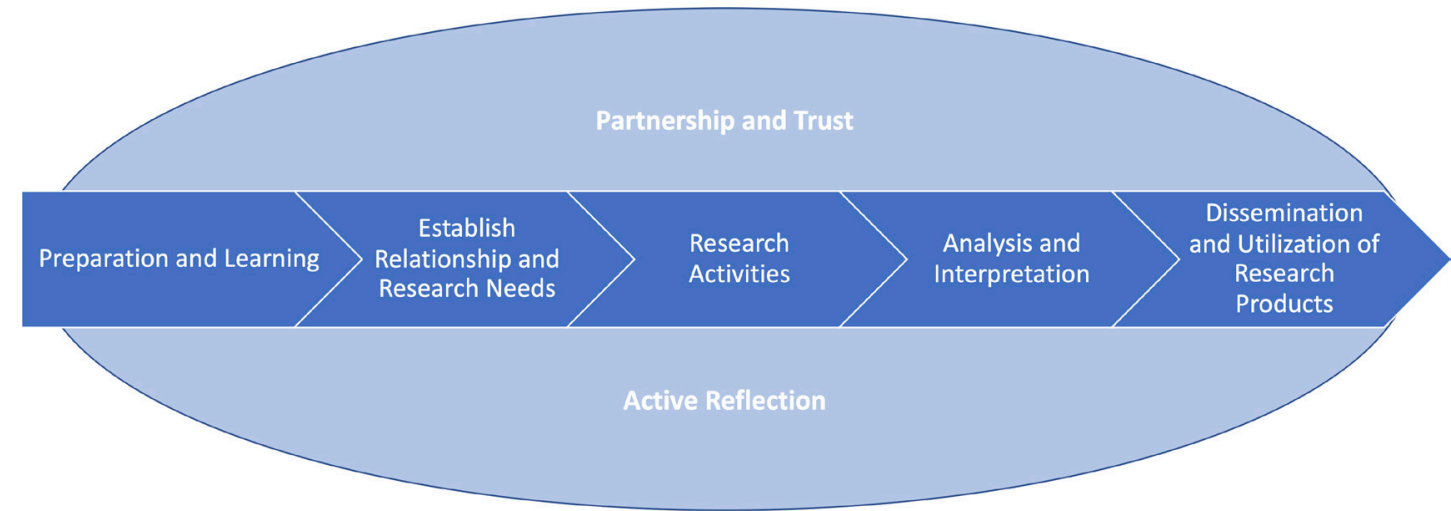

Figure 2 Synthesised model of Indigenous community engagement. 
personal motivations and on power differentials between them and communities as a way to embrace learning and move forward with true collaborative actions.

\section{DISCUSSION}

These recommendations synthesise and promote actionable recommendations for community engagement approaches with Indigenous peoples when engaging in health research. While detailing practices throughout the different stages of the research process, two overarching concepts were identified: the critical components of building partnership and trust, and pursing active reflection of one's interactions and approaches with community. Through the recommendations suggested in this work, we endeavour to provide direction to researchers in decolonising methodologies-a much needed impetus for avoiding a 'researcher knows best' and 'deficit-based' approach to research involving any Indigenous community as has been occurring in the scientific community.

The process of community engagement begins far before data collection-it begins with preparation and learning on behalf of the researchers, and this sets the tone for subsequent stages of the research. Important questions to consider before initiating a research project in an Indigenous community are: (a) why is it that some communities oppose research? and (b) for what reasons did some communities distance themselves from research? Researchers can begin by understanding the history of the relationship between research and Indigenous communities, and the experiences of oppression and assimilation Indigenous communities have faced historically and continue to experience. ${ }^{42}$ In addition to understanding the historical context, it is equally important to understand that the current health inequities are rooted in colonialism, ${ }^{16}$ a legacy propagated to this day. It is crucial that researchers do not move ahead with a research idea until they obtain a solid understanding of historical implications of research and colonialism.

Following this preparatory step, researchers need to establish relationships and earn their trust in local communities. One way to create a path for creating new connections is through seeking introductions from individuals who already have an established connection with the community. ${ }^{32}$ Nevertheless, it is important to recognise that it is the researcher's responsibility to invest significant amounts of time and energy in ongoing relationship building. ${ }^{28}$ It is worth investing in relationships as these will enable meaningful dialogues that will help define what is important within the community's selfdetermined health agenda. ${ }^{36}$ Only after determining community needs should the plan for research be considered and developed. In addition, formalising terms of reference or memorandums of understanding between researchers and community are fundamental to ensure the researcher commitment to the community's benefit. ${ }^{33}$

Details of the research plan need to reflect community strengths, ${ }^{28}$ and must be realistic, feasible and transparent, especially relating to the $\operatorname{costs}^{35}$ and timelines of the project. ${ }^{32}$ Researchers must also delineate which data are to be collected and agree on the limits for data collection. One way to increase community capacity and increase data collection appropriateness is through hiring local community members. ${ }^{53}$ Moreover, throughout the research process it is important to iteratively obtain feedback from communities, relating to data collection processes and research progress. ${ }^{27}$

Any collected data should belong to the communities which they are derived from, ${ }^{20}$ and any intellectual property rights generated from the research need to reflect this. ${ }^{39}$ Community members need to be consulted for interpreting findings, through creating a safe space for knowledge exchange between Indigenous knowledge and researcher views. No result should be deemed final unless approved by the community. Discussions for implications of the results should be also facilitated. ${ }^{60}$

The dissemination and utilisation of research results should reflect the objectives of the research project, that is, it should address the needs of the communities. Dissemination of any results relating to research in any format will require approval from communities, and researchers should honour requests for correcting misinterpretations. ${ }^{61}$ Shared authorship with communities is one step in ensuring that research results are interpreted at least in part with communities. ${ }^{61}$ Benefits of the research must be transparent, and shared with communities, especially relating to any commercialisation that results. ${ }^{26}$

The recommendations produced in this work represent one approach to engage Indigenous communities in research, and put a great emphasis on partnership and trust building practices, as well as in the important role of researchers' active reflection. This set of recommendations is different from others in that they overarch all stages of the research process and are focused on the actions that researchers should take in order to be mindful of their intentions, as well as respecting and honouring community interests. These recommendations are intended to bridge the gaps for researchers who want to forge a new beginning to go forward, in collaboration with Indigenous communities. Historical shortcomings cannot be forgotten-but they will help shape what the future of research can look like-a future where 'decolonising methodologies' predominate, and power paradigms shift back to communities that experience the impact of the research.

Funding agencies also have a role in upholding and enacting these recommendations at all stages of the grant cycle. Initial awarding of funds should be on demonstration of appropriate Indigenous community engagement, as vetted by Indigenous researchers and community representatives. This is already in progress at the Canadian Institutes of Health Research, which has increasingly engaged Indigenous elders and community members in peer-review committees. We encourage funding agencies to also consider policies and activities that can ensure ongoing appropriate engagement throughout 
the research process, a mechanism by which Indigenous community representatives and research participants can provide feedback on research engagement practices, and also confirming upholding of the recommendations through end-of-grant reporting requirements. These steps may be seen to be onerous or complex, dissuading Indigenous health research topics, but would be easy to demonstrate if true engagement and reflexivity was occurring.

One limitation of our study is that the methodology of qualitative synthesis may inevitably miss some of the recommendations currently in the literature. Search terms used in our strategy may have excluded key articles. Further, authors may not have detailed their community engagement approaches in their manuscript, as this is not mandated historically by journal editors and publishers. The new CONSIDER statement ${ }^{76}$ for Indigenous health research provides an advance by structuring reporting requirements in manuscripts, yet still does not address fully the longitudinal commitment required when engaging with an Indigenous community. Researchers who abided by Indigenous health research ethics and who did not proceed with publishing their work as requested by community would result in their approaches not being included in our review. Despite this, we believe that our review is comprehensive, and is also informed by our experience within our own research programmes. Another limitation is that the review is limited by what is available in the literature and may not address all questions that readers may encounter during the research process. We direct researchers to the local community to continuously seek feedback on desired community engagement processes that best fit to their individual cultural practices, being transparent about wanting to improve the researcher-community relationship is an important gesture to communities. Additionally, our review does not reflect the issue of sustainability of research projects as well as its results. We encourage readers to ensure proper community engagement, as well as an appropriate allocation of funds, in order to sustain projects and their positive results.

\section{CONCLUSIONS}

These recommendations synthesise and promote 37 actionable recommendations for community engagement approaches with Indigenous peoples when engaging in health research, while reinforcing the critical elements of partnership and building trust and active reflection by the researcher.

Contributors Study conception and design: AL-S and CB; data collection: CYL, $\mathrm{AL}-\mathrm{S}$ and $\mathrm{EB}$; analysis: CYL, AL-S, EB and $\mathrm{CB}$ and manuscript drafts and approval of final version: all authors.

Funding CYL was supported by the Canadian Institutes for Health Research Institute of Musculoskeletal Health and Arthritis Undergraduate Summer Studentship; AL-S was supported by the Canadian Institutes for Health Research Banting Postdoctoral Fellowship Award and CB was supported by the Canadian Institutes for Health Research New Investigator Award in Community-Based Primary
Healthcare, Canadian Institutes for Health Research Canada Research Chair (Tier 2) in Rheumatoid Arthritis and Autoimmune Diseases and a Canadian Institutes for Health Research Foundation Scheme Grant Award. The O'Brien Institute for Public Health (University of Calgary) provided funding support to this project. The funder of the study had no role in study design, data collection, data analysis, data interpretation or writing of the report.

Competing interests None declared.

Patient consent for publication Not required.

Provenance and peer review Not commissioned; externally peer reviewed.

Data availability statement The corresponding author had full access to all the data in the study and had final responsibility for the decision to submit for publication. Data are available upon reasonable request. The authors will provide data upon request.

Supplemental material This content has been supplied by the author(s). It has not been vetted by BMJ Publishing Group Limited (BMJ) and may not have been peer-reviewed. Any opinions or recommendations discussed are solely those of the author(s) and are not endorsed by BMJ. BMJ disclaims all liability and responsibility arising from any reliance placed on the content. Where the content includes any translated material, BMJ does not warrant the accuracy and reliability of the translations (including but not limited to local regulations, clinical guidelines, terminology, drug names and drug dosages), and is not responsible for any error and/or omissions arising from translation and adaptation or otherwise.

Open access This is an open access article distributed in accordance with the Creative Commons Attribution Non Commercial (CC BY-NC 4.0) license, which permits others to distribute, remix, adapt, build upon this work non-commercially, and license their derivative works on different terms, provided the original work is properly cited, appropriate credit is given, any changes made indicated, and the use is non-commercial. See: http://creativecommons.org/licenses/by-nc/4.0/.

ORCID iD

Cheryl Barnabe http://orcid.org/0000-0003-3761-237X

\section{REFERENCES}

1 Cochran PAL, Marshall CA, Garcia-Downing C, et al. Indigenous ways of knowing: implications for participatory research and community. Am J Public Health 2008;98:22-7.

2 Sterling RL. Genetic research among the Havasupai--a cautionary tale. Virtual Mentor 2011;13:113-7.

3 Kana'iaupuni SM. Ka'akālai Kū Kanaka: A Call for Strengths-Based Approaches from a Native Hawaiian Perspective. Educational Researcher 2005;34:32-8.

4 Humphery K. Dirty questions: Indigenous health and 'Western research'. Aust N Z J Public Health 2001;25:197-202.

5 Reid P, Cormack D, Paine S-J. Colonial histories, racism and healthThe experience of Māori and Indigenous peoples. Public Health 2019;172:119-24.

6 Canadian Institutes of Health Research, Natural Sciences and Engineering Research Council of Canada, Social Sciences and Humanities Research Council of Canada. Tri-Council policy statement (2): ethical conduct for research involving humans, 2018.

7 The First Nations Information Governance Centre. Ownership, control, access and possession (OCAP $\left.{ }^{\mathrm{TM}}\right)$ : the path to first nations information governance: the first nations information governance centre, 2014.

8 Kelley A, Belcourt-Dittloff A, Belcourt C, et al. Research ethics and Indigenous communities. Am J Public Health 2013;103:2146-52.

9 Lin CY, Loyola-Sanchez A, Hurd K, et al. Characterization of Indigenous community engagement in arthritis studies conducted in Canada, United States of America, Australia and New Zealand. Semin Arthritis Rheum 2019;49:145-55.

10 Austin S. Decolonizing methodologies: research and Indigenous people. J Health Psychol 2001;6:358-9.

11 Hyett S, Marjerrison S, Gabel C. Improving health research among Indigenous peoples in Canada. Can Med Assoc J 2018;190:E616-21.

12 Claw KG, Anderson MZ, Begay RL, et al. A framework for enhancing ethical genomic research with Indigenous communities. Nat Commun 2018;9:2957.

13 Whittemore $\mathrm{R}$, Knafl K. The integrative review: updated methodology. $J$ Adv Nurs 2005;52:546-53.

14 Haswell-Elkins M, Reilly L, Fagan R, et al. Listening, sharing understanding and facilitating consumer, family and community 
empowerment through a priority driven partnership in far North Queensland. Australas Psychiatry 2009;17 Suppl 1:S54-8.

15 Mitchell TL, Baker E, Mitchell E. Community-building versus career-building research: the challenges, risks, and responsibilities of conducting research with Aboriginal and native American communities. J Cancer Educ 2005;20:41-6.

16 Morton Ninomiya ME, Pollock NJ, Nathaniel J. Reconciling community-based Indigenous research and academic practices: knowing principles is not always enough. Soc Sci Med 2017;172:28-36.

17 Spencer MS. Insider-Outsider reflections from a native Hawaiian researcher and the use of community-based participatory approaches. Australas Psychiatry 2015;23:45-7.

18 First Nations Health Council Communications Advisory Committee and Communications Department. Moving forward together, 2011.

19 Lincoln YS, Guba EG, Pilotta JJ. Naturalistic inquiry. Newbury Park CA: Sage Publishing, 1985: 438-9.

20 Assembly of First Nations Environmental Stewardship Unit. Ethics in first nations research, 2009

21 Bailey J, Veitch C, Crossland L, et al. Developing research capacity building for Aboriginal \& Torres Strait Islander health workers in health service settings. Rural Remote Health 2006;6:556.

22 Baird R. Listening to our Aboriginal communities: how to engage in a respectful way, 2015.

23 Ball J, Janyst P. Enacting research ethics in partnerships with indigenous communities in Canada: "Do it in a good way". J Empir Res Hum Res Ethics 2008;3:33-51.

24 Bandler LG. Beyond chapter 4.7. Health Promot J Austr 2015;26:186-90.

25 Bartlett JG, Iwasaki Y, Gottlieb B, et al. Framework for Aboriginalguided decolonizing research involving Métis and first nations persons with diabetes. Soc Sci Med 2007;65:2371-82.

26 Beaton A, Hudson M, Milne M, et al. Engaging Māori in biobanking and genomic research: a model for biobanks to guide culturally informed governance, operational, and community engagement activities. Genet Med 2017:19:345-51.

27 Bell R, Tumilty S, Kira G, et al. Using a community based participatory research model within an Indigenous framework to establish an exploratory platform of investigation into obesity. Obes Med 2016;2:19-24.

28 Bharadwaj L. A framework for building research partnerships with first nations communities. Environ Health Insights 2014;8:15-25.

29 Bingham B. Aboriginal community-based primary health care research: developing community driven primary health care research priorities, 2013.

30 Brown JH, Whiteside M. Talking back: the changing nature of Indigenous health research feedback. Health Promot $J$ Aust 2002;13:34-9.

31 Brunger F. Guidelines for research involving Aboriginal communities in Newfoundland and Labrador, 2013.

32 Brunger F, Wall D. "What Do They Really Mean by Partnerships?" Questioning the Unquestionable Good in Ethics Guidelines Promoting Community Engagement in Indigenous Health Research. Qual Health Res 2016;26:1862-77.

33 Christopher S, Saha R, Lachapelle P, et al. Applying Indigenous community-based participatory research principles to partnership development in health disparities research. Fam Community Health 2011;34:246-55

34 Cooper EJ, Driedger SM, Creative DSM. Creative, strengths-based approaches to knowledge translation within Indigenous health research. Public Health 2018;163:61-6.

35 Couzos S, Lea T, Murray R, et al. 'We are not just participants-we are in charge': the NACCHO ear trial and the process for Aboriginal community-controlled health research. Ethn Health 2005:10:91-111.

36 Crooks CV, Snowshoe A, Chiodo D, et al. Navigating between rigour and community-based research partnerships: building the evaluation of the Uniting our nations health promotion program for FNMI youth. Can J Commun Ment Health 2013;32:13-25.

37 Duff D, Jesudason S, Howell M, et al. A partnership approach to engage Aboriginal and Torres Strait Islander peoples with clinical Guideline development for chronic kidney disease. Renal Society of Australasia Journal 2018:14:84-8.

38 Duffy G, Ross SJ, Woolley TS, et al. Processes and outcomes for a successful engagement between a medical school and a remote Indigenous community in North Queensland, Australia. Rural Remote Health 2013;13:2277.

39 Esler DM. Participatory action research in Indigenous health. Aust Fam Physician 2008;37:457-9.

40 Funnell S, Tanuseputro P, Letendre A, et al. "Nothing About Us, without Us." How Community-Based Participatory Research
Methods Were Adapted in an Indigenous End-of-Life Study Using Previously Collected Data. Can J Aging 2020;39:145-55.

41 Glass KC, Kaufert J. Research ethics review and Aborigina community values: can the two be reconciled? J Empir Res Hum Res Ethics 2007;2:25-40.

42 Harding A, Harper B, Stone D, et al. Conducting research with tribal communities: sovereignty, ethics, and data-sharing issues. Environ Health Perspect 2012;120:6-10.

43 Harfield S, Pearson O, Morey K, et al. Assessing the quality of health research from an Indigenous perspective: the Aboriginal and Torres Strait Islander quality appraisal tool. BMC Med Res Methodol 2020;20:79.

44 Haynes E, Marawili M, Marika BM, et al. Community-based participatory action research on rheumatic heart disease in an Australian Aboriginal homeland: Evaluation of the 'On track watch' project. Eval Program Plann 2019;74:38-53.

45 Hedges J, Garvey G, Dodd Z, et al. Engaging with Indigenous Australian communities for a human papilloma virus and oropharyngeal cancer project; use of the consider statement. BMC Med Res Methodol 2020;20:92.

46 Heffernan C, Herbert C, Grams GD, et al. The Haida Gwaii diabetes project: planned response activity outcomes. Health Soc Care Community 1999;7:379-86.

47 Jaworsky D. An allied research paradigm for epidemiology research with Indigenous peoples. Arch Public Health 2019;77:22.

48 Johnston Research Inc. Aboriginal community engagement strategy final report, 2011

49 Kassi N, Friendship K, Butler Walker J. Indigenous community food security in Yukon Territory. Arctic Institute of Community-Based Research, 2015.

50 Kerr S, Penney L, Barnes HM, et al. Kaupapa Maori action research to improve heart disease services in Aotearoa, New Zealand. Ethn Health 2010;15:15-31.

51 Khayyat Kholghi M, Bartlett G, Phillips M, et al. Evaluating an Indigenous health curriculum for diabetes prevention: engaging the community through talking circles and knowledge translation of results. Fam Pract 2018;35:80-7.

52 Liaw ST, Lau P, Pyett P, et al. Successful chronic disease care for Aboriginal Australians requires cultural competence. Aust N Z J Public Health 2011;35:238-48.

53 Maar MA, Lightfoot NE, Sutherland ME, et al. Thinking outside the box: Aboriginal people's suggestions for conducting health studies with Aboriginal communities. Public Health 2011;125:747-53.

54 Morton Ninomiya ME, Hurley N, Penashue J. A decolonizing method of inquiry: using institutional ethnography to facilitate communitybased research and knowledge translation. Crit Public Health 2020:30:220-31.

55 Naqshbandi Hayward M, Paquette-Warren J, Harris SB, et al. Developing community-driven quality improvement initiatives to enhance chronic disease care in Indigenous communities in Canada: the forge ahead program protocol. Health Res Policy Syst 2016;14:55

56 Oneha MF, Beckham S, Oneha S.;, Frances M. Re-Examining community based research protocols. Pac Health Dialog 2004:11:102-6.

57 Oneha Mary Frances Mailelauli'i, Oneha M, Mailelauli'i MF. The 'place' of data. Pac Health Dialog 2004;11:204-8.

58 Packer J, Turpin G, Ens E, et al. Building partnerships for linking biomedical science with traditional knowledge of customary medicines: a case study with two Australian Indigenous communities. J Ethnobiol Ethnomed 2019;15:69.

59 Peake RM, Jackson D, Lea J, et al. Meaningful engagement with Aboriginal communities using participatory action research to develop culturally appropriate health resources. J Transcult Nurs 2020:104365961989999.

60 Priscilla P, Pyett P, VicHealth Koori Health Research and Community Development Unit. Towards reconciliation in Indigenous health research: the responsibilities of the non-Indigenous researcher. Contemp Nurse 2002;14:56-65.

61 Quigley D. A review of improved ethical practices in environmental and public health research: case examples from native communities. Health Educ Behav 2006;33:130-47.

62 Team. RBwFNaPHR. Relationship building with first nations and public health: exploring principles and practices for engagement to improve community health - literature review. Sudbury, ON, 2017.

63 Ritchie SD, Jo Wabano M, Beardy J, et al. Community-Based participatory research with Indigenous communities: the proximity paradox. Health Place 2013;24:183-9.

64 Singer J, Bennett-Levy J, Rotumah D. "You didn't just consult community, you involved us": transformation of a 'top-down' Aboriginal mental health project into a 'bottom-up' community-driven process. Australas Psychiatry 2015;23:614-9. 
65 Thomas Y, Gray M, McGinty S. Occupational therapy at the 'cultural interface': Lessons from research with Aboriginal and Torres Strait Islander Australians. Aust Occup Ther J 2011;58:11-16.

66 Tremblay M-C, Martin DH, McComber AM, et al. Understanding community-based participatory research through a social movement framework: a case study of the Kahnawake schools diabetes prevention project. BMC Public Health 2018;18:N.PAG-N. PAG.

67 University of Calgary. Cultural protocol guidelines Ucalgary, 2012.

68 University of Manitoba. Framework for research engagement with first nation, Metis, and Inuit peoples, 2013.

69 Voyle JA, Simmons D. Community development through partnership: promoting health in an urban Indigenous community in New Zealand. Soc Sci Med 1999;49:1035-50.

70 Wahbe TR, Jovel EM, García DRS, et al. Building International Indigenous People's Partnerships for Community-Driven Health Initiatives. Ecohealth 2007;4:472-88.

71 Walker JD, Rowe R, Jones CR. Describing the process of ethical conduct of research in an Ontario-wide first nations diabetes research project. Can Med Assoc J 2018;190:S19-20.
72 Wilson S. Circle of engagement model: a cultural Guidebook to help build trust and collaborations between health planners, health trainers, health service providers. Educators and First Nations, 2014.

73 Wright M, Culbong T, Crisp N, et al. "If you don't speak from the heart, the young mob aren't going to listen at all": An invitation for youth mental health services to engage in new ways of working. Early Interv Psychiatry 2019;13:1506-12.

74 Young NL, Wabano MJ. Beyond the patient: lessons from community engagement in a rural first nation. Can Med Assoc J 2018;190:S16-18.

75 Zemits B, Maypilama L, Wild K, et al. Moving Beyond "Health Education": Participatory Filmmaking for Cross-Cultural Health Communication. Health Commun 2015;30:1213-22.

76 Huria T, Palmer SC, Pitama S, et al. Consolidated criteria for strengthening reporting of health research involving Indigenous peoples: the consider statement. BMC Med Res Methodol 2019;19:173.

77 Moher D, Liberati A, Tetzlaff J, et al. Preferred reporting items for systematic reviews and meta-analyses: the PRISMA statement. PLoS Med 2009;6:e1000097. 